\title{
Análise de Programas de Transferência de Renda no Brasil sob a Ótica e Prática de Atores Federais e Estaduais
}

\section{Income Transfer Programs in Brazil: the perspectives and practice of federal and state stakeholders}

\section{Elaine Martins Pasquim}

Mestre em Nutrição Humana pela Universidade de Brasília, Nutricionista do Ministério da Saúde.

Endereço: Ministério da Saúde, Esplanada dos Ministérios, Bloco

G, Cep 70058-900, Brasília, DF, Brasil.

E-mail: elaine_pasquimळyahoo.com.br

\section{Leonor Maria Pacheco Santos}

Pós-doutorado em Epidemiologia Materno Infantil pela London School of Hygiene and Tropical Medicine, Pesquisador Colaborador do Departamento de Nutrição da Universidade de Brasília.

Endereço: Campus Universitário Darcy Ribeiro, Faculdade de Saúde, Departamento de Nutrição, Cep 70910-900, Brasília, DF, Brasil.

E-mail: leopacœunb.br

\section{Resumo}

A pobreza, a fome e a desnutrição possuem múltiplos e complexos determinantes. A necessidade de uma renda capaz de garantir o direito humano fundamental à alimentação, essencial para a vida, há muito vem sendo discutida. No Brasil, experiências locais deram suporte à criação de programas nacionais de transferência de renda com condicionalidades. Este estudo teve por objetivo analisar de modo qualitativo, aspectos da percepção e prática dos atores envolvidos direta ou indiretamente nos programas Bolsa Escola, Bolsa Alimentação e Cartão Alimentação em nível nacional e estadual. Realizou-se entrevistas com gestores e informantes-chaves, além de análise de Atas de Conselhos e de pronunciamentos de parlamentares no Congresso. As metas dos programas indicam uma aparência universalizante, porém sua essência mostrouse fragmentada e seletiva entre os já focalizados. Apesar de relevantes na redução da pobreza, esses programas deveriam ser articulados e intersetoriais, reunindo diversas ações em diferentes áreas para conseguir melhorar a qualidade de vida de seus beneficiários, pois isoladamente não são capazes de solucionar a pobreza e a fome.

Palavras-chave: Transferência de Renda; Política Pública; Alimentação e Nutrição. 


\section{Abstract}

Causes of poverty, hunger and malnutrition are multiple and complex. Current and past discussions promote the idea of an income able to guarantee the human right to adequate food, which is fundamental to life. Local experiences in Brazil have supported the creation of national conditional cash transfer programs. The objective of the study was to perform a qualitative analysis about the perception and practice of the stakeholders directly or indirectly involved in the programs Bolsa Escola, Bolsa Alimentação and Car tão Alimentação in the federal and state levels. Program managers and key informants were interviewed, and minutes of Social Councils meetings and speeches of congressmen were analyzed. Programs objectives indicate an apparent universality; however, their essence revealed fragmentation and selection among the already targeted beneficiaries. Considering their importance in the reduction of poverty these programs should be articulated and interdisciplinary, integrating several interventions in order to improve the quality of life of their beneficiaries. Isolated, they are not capable of finding solutions for poverty and hunger.

Keywords: Cash Transfer Programs; Public Policy; Food and Nutrition.

\section{Introdução}

A pobreza, a fome e a desnutrição possuem múltiplos e complexos determinantes de difícil erradicação, que contemplam desde processos individuais, incluindo os biológicos, psicológicos, quanto os culturais, históricos, econômicos e políticos.

Almeida (2000) discute conceitos de pobreza que trabalham a "pobreza nutricional", que seria aquela em que os indivíduos ou famílias não possuem renda suficiente para adquirir uma cesta básica. Balsadi, Del Grossi e Takagi (2004) destacam que a fome prejudica a capacidade de aprendizado das crianças, reduz a produtividade de adultos, faz com que as pessoas fiquem mais suscetíveis a doenças e provoca a morte prematura, perpetuando a pobreza e a iniqüidade.

Os Estados têm obrigações advindas de acordos internacionais de respeitar, proteger e facilitar/prover o direito humano à alimentação adequada (DHAA). Esse direito realiza-se quando todos têm acesso a uma alimentação adequada, digna e sustentável, além de estarem livres da fome e da má nutrição (Valente, 2002). Os programas de transferência de renda (PTR), seja renda básica ou mínima, estão entre as políticas concebidas para garantir esse direito.

O marco nacional dessa discussão foi a aprovação, em 1991, do Programa de Garantia de Renda Mínima (PGRM) no Senado Federal, proposto por Eduardo Suplicy. Porém, Suplicy atribui a primeira proposta de renda mínima, instituída como imposto de renda negativo, a Antônio Maria da Silveira, em 1975 (Suplicy, 2002) (Silva, 2004).

No Brasil, iniciativas locais surgiram a partir de 1995. Em 2001, surgiram o Programa Nacional Bolsa Escola (PNBE), gerido pelo Ministério da Educação e voltado para crianças de 7 a 15 anos (Brasil, 2001a) e o Programa Bolsa Alimentação (PBA), do Ministério da Saúde (MS), para crianças de 6 meses a 6 anos, gestantes e nutrizes (Brasil, 2001b). Ambos com o critério de renda familiar per capita abaixo de R\$ 9o,oo e benefícios de R\$15, oo (máximo de três por família, ou seja, R\$45,0o). No início de 2003, foi criado o Programa Cartão Alimentação (PCA), gerido pelo Ministério Extraordinário de Segurança Alimentar (MESA), concedendo benefício de R\$ 50,oo por família à população com renda inferior a meio salário mínimo per capita (Brasil, 2003a). Os três programas alcançaram cober- 
turas expressivas de beneficiários no auge de sua implementação, ou seja, no final de 2003: o PNBE atingiu 8,3 milhões de escolares; o PBA, 2,3 milhões de pré-escolares, gestantes e nutrizes, e o PCA, cerca de 9,9 milhões de pessoas (Brasil, 2003b; Brasil, 2004C; Balsadi e col., 2004).

Nos três programas, o benefício era pago diretamente à população por meio de cartões magnéticos, nas agências da Caixa Econômica Federal (CAIXA), postos de atendimento do Caixa Aqui, ou lotéricas. Cabia aos municípios, cadastrar, selecionar as famílias e acompanhar condicionalidades, a saber: freqüência escolar de no mínimo 85\% para o PNBE, ações de saúde e nutrição para o PBA e controle de notas fiscais de compra de alimentos para o PCA. Os três programas foram unificados no Bolsa Família no final de 2003 (Brasil, 2004a), que não é objeto de análise. Este estudo visa descrever experiências sobre as estratégias adotadas na implementação dos programas, buscando apreender, na ótica dos principais atores envolvidos, os aspectos positivos e os pontos de estrangulamento.

\section{Material e Métodos}

O estudo, de natureza qualitativa, analisou o PNBE, PBA e PCA do ponto de vista de seus atores relevantes. Foram entrevistados os gestores de Minas Gerais e de estados pertencentes à região Nordeste, pois, apesar de os programas Bolsa Escola e Bolsa Alimentação estarem presentes em todos os estados, o mesmo não ocorria com o CA. Nesse caso, os gestores optaram por implantá-lo de início nas regiões consideradas mais vulneráveis, ou seja, semi-árido e norte de Minas Gerais. Destaca-se, ainda, que o Bolsa Escola não possuía a instância estadual, sendo entrevistado somente o gestor federal.

Para o PBA, 10 gestores estaduais foram incluídos no estudo, provenientes de: AL, BA, CE, MA, MG, PB, PE, PI, RN e SE. No caso do PCA, foram estudados gestores de quatro estados cuja localização foi possível à época do estudo, considerando que a pesquisa foi posterior à extinção dos programas (com mudança de atores sociais e instituições), sendo eles: AL, BA, PI e SE.

Realizaram-se, portanto, as seguintes entrevistas, por meio de formulários semi-estruturados: (a) um gestor federal do PNBE, dois do PBA e três do PCA; (b) dois representantes da CAIXA; (c) 10 representantes das coordenações estaduais do PBA e quatro do PCA; (d) representante de Organização não-governamental (ONG) indígena; (e) representante de ONG quilombola.

Foram, ainda, analisados pronunciamentos de parlamentares em plenário do Congresso Nacional e atas das reuniões do Conselho Nacional de Saúde (CNS), Comissão Interinstitucional de Alimentação e Nutrição (CIAN) e Conselho Nacional de Segurança Alimentar e Nutricional (Consea).

O instrumento escolhido para esta pesquisa foi o formulário elaborado no formato semi-estruturado com o objetivo de direcionar as idéias, sem limitar informações complementares fornecidas, ao contrário, estimulando-as nos casos em que houve a introdução de temas novos relevantes. Para a realização dessas entrevistas foi privilegiado o contato direto, mas, no caso dos gestores estaduais, houve situações em que foi necessário coletar as informações por telefone, o que ocorreu com duas entrevistas de representantes do PBA e três do PCA.

Apresentou-se Termo de Consentimento Livre e Esclarecido e, para as entrevistas por telefone, o consentimento para a pesquisa e para a gravação da conversa foram solicitados e gravados, conforme aprovado no Comitê de Ética da Universidade de Brasília.

As entrevistas foram analisadas e sistematizadas a partir de leituras sucessivas. Os resultados foram categorizados conforme o ciclo de vida de uma política ou programa social (Draibe, 2001).

\section{Resultados e Discussão}

\section{Formulação dos programas: formação da agenda política}

Nenhuma sociedade, segundo Oszlak e O'Donnell (1976), possui a capacidade nem os recursos para atender comodamente a lista de necessidades de seus integrantes. Somente algumas são socialmente problematizadas, dependendo de seu significado para os atores (visibilidade, importância, reconhecimento), de recursos disponíveis e do poder relativo dos atores para sua resolução, como fatores mais agregados à estrutura social.

A prioridade quanto à questão da fome no Brasil contemporâneo teve início em 1993, quando Herbert de Souza criou a Ação da Cidadania contra a Fome, a 
Miséria e pela Vida, trazendo esse tema para a agenda pública. Nesse período, o presidente do Partido dos Trabalhadores (PT), Luiz Inácio Lula da Silva, enviou ao então Presidente Itamar Franco um Programa de Segurança Alimentar, propondo a criação de um fórum de parceria entre governo e sociedade. Itamar Franco divulgou o Mapa da Fome, elaborado pelo Instituto de Pesquisas Econômicas Aplicadas, revelando 32 milhões de indigentes e criou o Conselho de Segurança Alimentar e Nutricional (Consea). Em 1995, porém, o recém empossado Presidente Fernando Henrique Cardoso (FHC) extinguiu o Consea e instituiu o Comunidade Solidária para combater a fome e a miséria; em 1999, lançou o Comunidade Ativa para propor projetos de desenvolvimento sustentável (Vasconcelos, 2005). Alguns autores já ressaltaram que a agenda social do governo FHC promoveu o desmonte de programas e instituições relacionados à segurança alimentar: nesse período foram extintos, além do Consea (1995), a Legião Brasileira de Assistência (LBA) (1995), o Instituto Nacional de Alimentação e Nutrição, INAN (1997) e, posteriormente, o Programa Emergencial de Distribuição de Alimentos, Prodea (2002) (Valente, 2003). Em 1999, Antônio Carlos Magalhães (ACM) propôs a constituição da Comissão Mista de Combate à Pobreza, que criaria, em 2001, o Fundo Constitucional de Combate e Erradicação da Pobreza (FCEP), com objetivos nitidamente eleitoreiros (Chaibub, 2004).

A criação do PNBE surgiu de uma demanda da sociedade para o Estado. Em 1986 Cristovam Buarque, então reitor da Universidade de Brasília criou o Centro para Estudos Contemporâneos Brasileiros, no qual foi concebida, em 1987, a estratégia que se tornaria o Bolsa Escola. Em 1994, Cristovam Buarque foi eleito para o Governo do Distrito Federal, implementando o Programa Bolsa Escola (distrital) em 1995. Em 1998, o Ministro da Educação lançou o PGRM-Bolsa Escola, para o qual o Governo Federal financiaria aos municípios metade dos custos. Porém, somente em 2001, por interesses eleitorais, segundo alguns autores, consolidou-se o PNBE (Aguiar e Araújo, 2002; Britto, 2004).

As entrevistas com representantes do PBA evidenciam que o programa surgiu de uma demanda do governo para a sociedade, diante da necessidade colocada pela própria Presidência da República, na época. A demanda pelo PBA foi corroborada pelos técnicos do Ministério da Saúde, ao sentirem a necessidade de substituir o Incentivo ao Combate às Carências Nutricionais (ICCN), programa freqüentemente denunciado por desvios de recursos, dificuldade de armazenamento e distribuição paternalista dos alimentos (leite e óleo). Destaca-se o fato de o programa ter sido discutido e aprovado na Comissão Intergestores Tripartite (Coitinho e Leão, 2004). Apesar disso, não foi aprovado pela própria instância de controle social do órgão de saúde em que surgiu, como será mostrado a seguir.

A proposta Fome Zero elaborada pelo Instituto de Cidadania (2001) a partir do Programa de Segurança Alimentar já citado, tornou-se um dos principais projetos políticos para a eleição do Presidente Lula, em 2002. O PCA, gerido pelo extinto MESA, foi uma das ações dessa proposta a ser implantada no início do governo.

\section{Definição das estratégias de implementação}

Segundo Poulantzas (1985), as políticas do Estado são resultantes do confronto entre atores; mesmo nos casos em que as massas estão fisicamente excluídas de certos aparelhos, essas lutas sempre têm efeito em seu seio, inclusive existindo contradições interestatais entre setores e aparelhos do Estado. 0 autor afirma que essas contradições são necessárias à sua organização.

As principais oposições levantadas pelos representantes da gestão nacional durante as entrevistas foram: para o PNBE, o valor do benefício; para o PBA, a possibilidade de má utilização do recurso e o aumento de carga de responsabilidade pela mulher; para o PCA, a perda de controle por parte dos prefeitos (referente tanto aos recursos pagos diretamente aos beneficiários, quanto ao empoderamento dos Comitês Gestores). Outros questionamentos foram: a possibilidade de abusos por donos de mercados (retenção de cartões e venda de produtos com preços acima do mercado), a sugestão de discutir PTRs mais amplos e o não relacionamento da fome com questões/ações de saúde.

Houve intenso debate sobre a forma de concessão do PCA, pois a proposta inicial era operacionalizá-lo como "Ticket Alimentação", à semelhança do programa americano "Food Stamps" (Instituto de Cidadania, 2001). Porém, tendo em vista o êxito e a aceitação dos programas de transferência de renda (PTR) já em curso (PNBE e PBA), a decisão política recaiu sobre a criação de mais um PTR.

O PBA e o PCA foram discutidos entre governo e sociedade civil, em conselhos de controle social, antes 
de seus lançamentos. O mesmo não ocorreu com o PNBE. Segundo Vasconcelos (1988), as instituições das políticas sociais são por excelência o campo de luta pela hegemonia. A importância da luta ideológica está no fato de que cada grupo com pretensões hegemônicas busca articular interpelações democráticas como idéias de participação, de igualdade, de justiça, de direitos a seu discurso ideológico e a sua prática político-institucional concreta. Grupos dominantes buscam convencer a sociedade civil de que a concretização daquelas interpelações irá ou está sendo realizada.

Essa relação de forças e interesses pode ser percebida pelas falas descritas nas Atas tanto do CNS quanto do Consea, onde se discutiram respectivamente PBA e PCA: [..] já foi um pacto aprovado nos três níveis de governo. Por isso, espero que este Conselho aprove o projeto $e$ depois, constitua Comissão para promover o acompanhamento. Nós vamos implementar o Programa, porque temos a convicção de que estamos fazendo o melhor para os cidadãos. (Representantes do MS à época - sobre o PBA em 2002.)

Conselheiro (...) observou que o Programa seria executado pelo Governo Federal independentemente da aprovação do CNS e registrou a sua preocupação com relação aos Programas desarticulados que estavam sendo implementados nos três níveis de governo. (Sobre o PBA, em 2002.)

É importante se ter um Consea nacional militante em favor do Programa Fome Zero. (Representante do PCA, em 2003.)

O primeiro Objetivo de Desenvolvimento do Milênio é "erradicar a extrema pobreza e a fome", sua segunda meta é reduzir a proporção da população que tem fome. 0 indicador mais recomendado internacionalmente para acompanhar essa meta é a prevalência de crianças com menos de 5 anos de idade que estejam abaixo do peso, pois a fome e a pobreza impactam diretamente no estado de saúde e nutrição dos indivíduos (IPEA, 2004). Desconsiderar o aspecto de saúde ao tratar de pobreza e fome desconsidera também o acesso a um direito social fundamental (atenção nos serviços de saúde) e a sua manifestação mais imediata no estado nutricional e de saúde do indivíduo, da família e das comunidades.

Offe (1984) afirma que as estratégias da política social são determinadas pela tentativa de resolver uma “meta-problema”, satisfazendo, simultaneamente, as exigências das políticas admitidas e as necessidades previsíveis. As falas confirmam a necessidade de resolução da "meta-problema", a fome, mas identifica a existência de imposição no CNS e de cooptação no Consea para a manutenção da hegemonia. No caso do PBA, apesar das discussões em conselho, não houve real aprovação:

Conselheira (...) lembrou que o Conselho Nacional de Saúde não aprovara o PBA, considerando que apresentava uma série de imperfeições relativas a sansão penal para as mães que apresentassem dados falsos $e$ uma série de atividades a serem cumpridas, conforme agenda de compromisso. (Sobre o PBA, reunião do CNS, em 2003.)

A atenção primária à saúde, a ambulatorial ou o Programa Saúde da Família, dividem a responsabilidade de maximizar a extensão na qual serviços de saúde podem superar as desvantagens sociais e seus efeitos adversos com a saúde pública (Starfield, 2004). No entanto o Programa Saúde da Família não existe em todos os municípios e muitos serviços de saúde não conseguem atender toda a demanda existente. Os ACS apoiavam, sobretudo, o PBA e o PCA desde o cadastramento. O PBA apresentava uma agenda de compromissos com itens que se constituíam em direitos da população (como pré-natal, vacinação, monitoramento do crescimento infantil) e que deviam ser ofertados pelos serviços de saúde, os quais nem sempre se apresentavam adequados às novas demandas.

Um representante do PBA esclareceu que as sanções eram apenas para agentes municipais e que a agenda de compromissos era composta de ações ofertadas pelos municípios. Assim, a cobrança seria maior sobre estes do que sobre os beneficiários, o que, segundo entrevistas, na prática aconteceu. Porém, o cumprimento da agenda continuou sendo cobrado, o que provavelmente deve ter impedido a aprovação final pelo Conselho.

\section{Implementação e sistema de gestão}

No tocante às políticas sociais, o período FHC foi marcado por uma atuação difusa, na qual diferentes instâncias do governo federal elaboraram e executaram ações e programas voltados para o combate à pobreza. Como conseqüência, as políticas sociais, dentre as quais o PBA e PNBE, apresentaram-se de maneira desarticulada e desconexa, resultando em programas e 
ações sobrepostos ou concorrentes (IPEA, 2003). Na prática, evidenciou-se a fragmentação entre programas e órgãos e possíveis conflitos de interesses. 0 incentivo à educação, à alimentação saudável, à mobilização social para geração de renda e emprego e um monitoramento do impacto dos programas na renda, no estado nutricional e na freqüência escolar, indicam que a união dos programas, interdisciplinares e intersetoriais, seria mais resolutiva, com ações provavelmente mais globais e integrais.

Houve parcerias para a mobilização de atores estratégicos de sustentação e cooperação nas três esferas do governo, como o agente operador das transferências (CAIXA), os órgãos de controle externo e as instâncias locais. Para o PNBE, as Unidades da Federação não eram atores importantes como se percebe na entrevista com seu representante federal:

O Estado não tinha um papel na implementação do Programa. Teria sido melhor com os estados-seria mais viável. Quem escolhia as famílias eram os municípios que tinham cotas de vagas. (Gestor federal do PNBE)

O PBA priorizou a gestão municipal e os estados agiram reforçando e cobrando processos (cadastros, acompanhamentos, metas) de seus municípios. Estes, em alguns casos, chegavam a contatar diretamente a esfera federal, tamanho o grau de centralização das ações, o que pode ter fragilizado o poder descentralizado das Secretarias Estaduais de Saúde, conforme preconiza o Sistema Único de Saúde (SUS). Essa ameaça a um princípio do SUS não deve ser desconsiderada, pois a descentralização parte da idéia de que quanto mais perto do fato a decisão for tomada, mais chance haverá de acerto (Brasil, 1990).

Atropelou o estado. (PBA-Minas Gerais)

Havia contato direto entre o nível federal e municípios. (PBA-Sergipe)

Ministério fez toda a questão legal com o município e o estado perdeu o controle. (PBA-Bahia)

$O$ estado não tinha controle sobre isso [benefícios suspensos]. Município e CAIXA recorriam direto ao Ministério da Saúde. Só na adesão o estado era importante. (PBA-Piau).

Diferentemente dos demais programas, o PCA tentou organizar uma gestão mais participativa por meio de Comitês Gestores, cuja idéia teria surgido das experiências-piloto:

Escolheu-se uma cota [...] [para Guaribas e Acauã, mas] era tudo [indicado] do prefeito, aí que se percebeu a importância de se ter um controle social. (Gestor federal do PCA)

Outra representação federal do PCA expressa a vantagem dessa opção:

É mais participativo, nos outros programas eram as prefeituras que controlavam e no Comitê [Gestor] 2/3 era da sociedade [...] dava mais transparência, visibilidade e mobilização. (Gestor federal do PCA)

O PNBE coordenou o programa de modo centralizado e apesar da aparente descentralização promovida pelos demais. Na verdade, o que se nota é que o poder de decisão e participação real foi mais efetivo no PCA por causa da estratégia de Comitês Gestores. Esses Comitês articulavam políticas e programas entre Secretarias, ONGs, Sociedade Civil, na tentativa de melhorar a economia local e a geração de trabalho e renda. Seu diferencial foi a atribuição de atuação na gestão local e não só no acompanhamento e controle social.

No âmbito estadual, representantes do PBA citaram que seu papel incluía: capacitação no sistema informatizado, seguido do acompanhamento técnico, depois pelo apoio político, e então, o apoio junto à CAIXA, às supervisões e apoio para digitação dos cadastros. Representantes do PCA citaram como suas atribuições majoritariamente a capacitação e a supervisão, seguidas de orientações e o apoio para averiguação de denúncias.

Representantes do PBA indicaram a necessidade de capacitações mais estruturantes, enquanto os do PCA sugeriram maior valorização da experiência dos estados nas capacitações. As principais necessidades de mudanças sugeridas pelos estados no caso do PBA e PCA incluíram: combate à fragilidade política causada pelas instabilidades orçamentárias; evitar os fins eleitoreiros e possíveis reorientações que ocorrem em mudanças de governo; traçar estratégias de estabilização e de maior respeito aos cidadãos; melhor infra-estrutura; revisão do acompanhamento de condicionalidades.

$\mathrm{Na}$ esfera federal, a urgência política manifestouse pela necessidade de garantir resultados para a sociedade, direcionando uma estratégia mais centralizadora e, na esfera municipal, pela necessidade de controle dos cadastros. Dessa forma, a intenção de combater a fome e a pobreza parece esconder a busca pela legitimação em época de eleição. Exemplos de proble- 
mas políticos enfrentados são mostrados a seguir: Foi publicado na Folha de S. Paulo: "Bolsa-Escola beneficia apadrinhados de políticos" [...]. Em Minas Gerais [...] um dos beneficiados tem carro, casa própria e até antena parabólica. [...] Alguém culpa o Prefeito, que culpa a Secretária da Educação, que culpa o $M E$, onde o programa é totalmente desburocratizado, não havendo necessidade nem de comprovação da renda mensal das famílias [...] O Prefeito da cidade de Juatuba instado pelo Vereador Otto Barroso, respondeu: "Você sabe que esse programa é político; é eleitoreiro [...]". Mas lá mesmo, parentes do Vice-Prefeito, do Presidente da Câmara de Comerciantes e até de advogados tiveram acesso aos parcos $R \$ 15$ [...] Uma senhora, perguntada sobre a sua renda familiar, falou que não sabia direito, até porque não ganhava quase nada [...] alegou que o pessoal da Secretaria mandou-a inventar um número como $R \$ 200$ ou $R \$$ 3oo. Ela, então, disse que não iria escrever valor algum [...] Resultado: mãe de uma prole grande ficou sem nenhum centavo. (Parlamentar em pronunciamento do Senado em 24/o9/20o1, sobre o PNBE.)

Muda prefeito, muda tudo. (Fala de PBA-Sergipe durante entrevista.)

Houve um município que só selecionava os favores políticos. (PBA-PE em entrevista)

Começou bom, a filosofia era ótima, a operacionalização foi boa, mas cedeu às pressões políticas (referindo-se à desestruturação do Comitê Gestor, passando a responsabilidade pelo cadastramento para as prefeituras, sem controle pela sociedade). (Alagoas - PCA em entrevista)

Teve $100 \%$ de viés político. Era época de eleição. Não deveriam terfeito nessa época. (PBA-MG)

Era preciso dar mais tempo ao programa em alguns municípios, mas havia pressa em se fazer logo e se chegar ao número [planejado] de municípios. (PCA-BA)

\section{Seleção de beneficiários}

O cadastro dos beneficiários era responsável por reunir as informações sobre aqueles que necessitavam das ações do governo. $O$ tipo de cadastramento adotado foi um grande motivo de discussão. O PBA optou, primeiramente, pela utilização do Cadastro dos Usuários do Sistema Único de Saúde (CadSus). Contudo, a partir da determinação do Decreto Presidencial $n^{\circ}$ 3.877, instituindo o Cadastro Único (CadÚnico) houve alteração no processo de cadastramento pelo programa (Coitinho e Leão, 2004). Mudanças governamentais historicamente, no Brasil, levam à descontinuidade de políticas públicas. Com o novo governo, e o surgimento do PCA, houve inicialmente uma tentativa de desqualificação do CadÚnico, que acabou sendo utilizado do mesmo modo. Representantes federais do PCA revelaram os motivos da não aceitação do CadÚnico: Já pegou pronto. Não tinha tempo nem condições políticas para fazer outro. $O$ cadastro do governo anterior tinha cobertura desigual. (Gestor federal do PCA) A idéia inicial era que os beneficiários não passassem pelo CadÚnico, mas como era doação em dinheiro fomos orientados a usar o CadÚnico. Queríamos que os municípios tivessem uma liberdade maior como acontece com os programas do leite. (Gestor federal do PCA)

Uma parlamentar, no Senado, expôs sua indignação sobre o impasse quanto à descontinuidade e possível rejeição do Cadastro Único pelo PCA, que acabou, ao final, revendo sua decisão e adotando-o, como já era realizado pelo PNBE e PBA:

o jornal Folha de S. Paulo publica [...]: "Após checagens, cadastro único tucano é aprovado por ministério. [...] Essa era uma afirmação que fazíamos aqui há dois anos. (Abril/2005.) (Pronunciamento parlamentar no Senado)

Para o mesmo Cadastro foram variadas e em geral desconexas as estratégias adotadas pelos municípios. Britto (2004) coloca que os municípios foram os responsáveis pela implementação do PNBE, gerando variadas formas de identificação dos beneficiários, como: feita pelas próprias escolas, por filas, por critérios geográficos ou visitas domiciliares. Os gestores estaduais do PBA afirmaram que o cadastramento foi realizado por três Secretarias (Ação Social, Educação e Saúde) de modo desconexo. A maioria afirmou ter ocorrido visita domiciliar por Agentes Comunitários de Saúde (ACS).

Segundo Porto (2003) sobre o PCA, "nunca houve nenhum novo cadastramento [...] o que havia era a validação desse cadastro [CadÚnico] por parte do Comitê Gestor [...] pela internet [...] da lista de famílias filtradas segundo os critérios do PCA”. Essa informação também aparece na entrevista com representante nacional do PCA:

Os comitês gestores não cadastraram, utilizaram a listagem do CadÚnico dos outros programas e davam 
preferência para aqueles que estavam cadastrados, mas não estavam recebendo [...] Não conseguimos colocar novos beneficiários por dificuldade de inscrição no cadastro da CAIXA.

Gestores estaduais do PCA confirmaram o uso do cadastro dos programas anteriores sem visita domiciliar ou mutirão para seleção inicial.

Aproveitou o Cadastro do FHC. (PCA-AL.)

Aproveitavam o cadastro único disponível na internet. (PCA-BA.)

Segundo Porto (2003), somente aqueles articulados ao setor saúde faziam verificações posteriores apoiados pelos Agentes Comunitários de Saúde. Assim, percebe-se o papel fundamental exercido pelo Programa Saúde da Família, segundo o qual a atenção à saúde deve ser organizada por meio de visitas domiciliares. Com esse tipo de visita é possível melhorar a identificação das famílias com real vulnerabilidade, reduzindo fraudes. Ao discutir a seleção de beneficiários, o acesso dos mais vulneráveis torna-se tema relevante. As entrevistas com representações de ONGs quilombolas e indígenas revelaram dificuldades de inserção dessas populações no programa.

$\varepsilon$ É bom para as comunidades, mas não contemplam as diferenças. [...] Os indígenas que se inscreveram nos programas foi (sic) via prefeituras [...] aonde os prefeitos têm sensibilidade e fizeram o cadastro. Os índios acreditam haver três problemas: documento, repassee cadastro. Para cadastrar tem que ter documentação. os que estão mais longe ficam longe de caixas eletrônicos, o ideal era que os programas fossem coletivos. (ONG indígena.)

o cadastro único dos quilombolas não aconteceu. Começou no Maranhão, mas ainda não foi concluído. Se possível mudar algo nos programas, mudaria o cadastro, para que pudesse se adequar à realidade das populações específicas. (ONG quilombola.)

Apesar de o discurso ter como aparência a universalidade, a sua essência revela restrições que impediam o acesso de certos grupos: cotas ou exigências do cadastro, como documentação civil e comprovante de residência. As cotas para o PNBE basearam-se em projeções do IDH (Índice de Desenvolvimento Humano), do número de pessoas da PNAD (Pesquisa Nacional de Amostra de Domicílios) e do INEP (Instituto Nacional de Estudos e Pesquisas Educacionais). No caso do PBA foram baseadas na estimativa de desnutrição do
NUPENS/USP “ Núcleo de Pesquisa em Nutrição e Saúde da Universidade de São Paulo (Coitinho e Leão, 2004). Para o PCA, segundo Porto (2003), o comitê selecionava os mais prioritários dentro das vagas, “ainda que tivesse que realizar aquela cruel tarefa de escolher entre os mais pobres dos pobres". Seus critérios incluíam dados do CadÚnico: renda familiar per capita de até o,5 salário mínimo per capita, número de idosos, deficientes ou portadores de doenças crônicas, presença de gestantes, nutrizes ou crianças menores de 6 anos e 11 meses, mulheres chefes de família, relação de emprego, terra e trabalho. Sua experiência mostrou que os comitês atuaram na verificação do cadastro "excluindo dos potenciais beneficiários [grifo do autor] do PCA cerca de 30\% das famílias cadastradas". Semelhante exclusão no PNBE foi identificada por Britto (2004), que verificou casos repetidos de exclusão de possíveis beneficiários porque o município havia atingido sua estimativa de cobertura. Essa seleção entre os que se encaixam no critério legal, já focalizado, é uma violação de direito. Segundo Stein (2005), as estratégias de implementação de redes de proteção social destacam-se por seu papel contraditório, pois focalizam e reduzem direitos, ao mesmo tempo em que utilizam mecanismos descentralizados e participativos que envolvem diferentes segmentos sociais. Além disso, a autora cita o risco de armadilha da pobreza, em que a focalização não se volta para as necessidades dos beneficiários, visando um atendimento equânime, e sim para a ampliação da cobertura vinculada a um mesmo volume de recursos. Assim, os programas apresentariam um caráter discriminatório, limitando beneficiários.

Para Draibe (2001), fatores facilitadores e obstáculos condicionam positiva ou negativamente o cumprimento de objetivos. Os representantes federais dos três programas citaram como facilitadores da implantação a demanda pela sociedade e a decisão política.

Quanto aos obstáculos, o gestor nacional do PNBE citou dificuldade de transmissão de dados do cadastro em municípios com internet discada, envio repetido de cadastros pelos municípios e desaparecimento de lotes com quase um milhão de cadastros na CAIXA. O gestor nacional do PBA citou atraso da CAIXA na entrega do cartão e no pagamento; precariedade dos equipamentos de informática; dificuldade para realizar o acompanhamento devido à falta de recursos hu- 
manos; dificuldade de seleção de beneficiários nos grandes municípios e alteração do critério de seleção somente para risco social não considerando o estado nutricional. 0 gestor nacional do PCA citou a defasagem nos dados cadastrais e a existência de aproximadamente 30\% de famílias no cadastro que não tinham direito ao benefício, além da dificuldade de transmissão dos dados das prefeituras para a CAIXA e viceversa. Um representante da CAIXA citou como dificuldade o mapeamento da pobreza (requer infra-estrutura); as dificuldades de acesso (grande dificuldade de entrega de cartões e benefícios às comunidades isoladas); a dificuldade dos grandes centros em mapear populações de rua, sem teto e catadores de lixo, por falta de endereço fixo.

A principal dificuldade para todos os gestores nacionais dos programas foi o cadastro, seguido de problemas operacionais e de comunicação entre Agências da CAIXA, sistemas, municípios e beneficiários. Diante disso, o repasse ágil e seguro apresentado como vantagem do cartão magnético, em entrevista com representante da CAIXA, na verdade ficou prejudicado. Segundo entrevistado federal do PCA: "A CAIXA considerou a informação como sujeita a sigilo bancário e se portou como agente bancário e não de fomento social”. o Cadastramento era exigido, porém sem repasse de recurso para os estados e municípios, dificultando a organização local, por ser uma atividade não prevista na rotina de seus funcionários. Lembrando Fagnani (1998), nota-se que a direção do gasto não alcançava os segmentos mais carentes, e o montante do gasto não era compatível com a dimensão das carências sociais, pois as cotas não incluíam todos os portadores de direito.

No âmbito estadual, segundo representantes do PBA, o maior fator facilitador para a implementação foi o apoio federal. Para o PCA, as respostas foram geralmente baseadas na organização municipal como: prioridade aos municípios envolvidos em programas de mobilização, facilidade de seleção de beneficiários por municípios pequenos, disponibilidade do Comitê Gestor; CadÚnico organizado. Portanto, apesar de os gestores estaduais do PBA perceberem a centralização como algo que "atropelou os estados", além de ferir as diretrizes do SUS, reconhecem que, se esse papel não fosse assumido pela esfera federal, teria apresentado maior dificuldade na implantação.
Quanto aos obstáculos mais citados pelos estados na adesão, os gestores do PBA citaram dificuldades políticas; seguidas pela preferência pelo ICCN e a perda de controle pelo estado; por último, a dúvida sobre o bom uso do recurso pela população. Para o PCA, foram lembradas divergências nas indicações do Comitê Gestor e pressão para entrega da responsabilidade do cadastro à prefeitura. Aparentemente, as prefeituras eram capazes de bloquear o processo de implantação dos programas. Caso houvesse decisão política local pela não-adoção do programa e não cessão de funcionários para a execução, a população ficava privada do benefício até que algum tipo de coerção ao município se fizesse.

Para o cadastramento dos beneficiários, os representantes estaduais do PBA citaram como obstáculo a falta de prioridade a áreas de risco; cadastros incompletos/incorretos/ fraudados/ilegíveis; empresas terceirizadas que não passavam o arquivo retorno; o desvio/ sobrecarga de função dos ACS. Para o PCA, a maioria citou a falta de controle da mudança de perfil de beneficiários; a falta de infra-estrutura, o cadastro mal feito, a impossibilidade de cadastrar novos beneficiários e a dificuldade de acesso à internet. Porto (2003) afirma não haver "formas de controle público do cadastramento"; ocorrendo falta de cadastramento de famílias elegíveis, por posições políticas contrárias às suas ou por simples negligência.

As dificuldades relacionadas ao cadastramento de pessoas fora do perfil foi um problema comum e importante em todos os programas. A impossibilidade de se cadastrar novos beneficiários no PCA ocorreu porque no início só foi permitida a inclusão após capacitações, mesmo após o envio das Atas. Foram citados, ainda, a dificuldade de inscrição de beneficiário no NIS pelo fato de as prefeituras não conseguirem passar cadastros para o Datasus, deixando essas pessoas fora do programa; e o fato de as prefeituras não terem a relação de beneficiários, pois a informação se perdia por excesso de secretarias responsáveis por acompanhar o programa.

O potencial interesse financeiro e a falta de compromisso de empresas terceirizadas para digitação do cadastro certamente afetou os programas, como se pôde verificar nas perdas de arquivos-retorno no término do contrato. Segundo Coimbra (1987), as relações sociais para a execução dos programas não são 
simples relações entre Estado e beneficiários; elas envolvem também empresariado e seus interesses.

\section{Divulgação, informação e capacitação}

As capacitações do PBA e do PNBE, inclusive as da CAIXA, limitaram-se a questões operacionais, não discutindo mobilizações locais, o que diminuiu a possibilidade de resolução de inúmeros determinantes da fome e da desnutrição. Entretanto, o PCA organizou suas capacitações sob a ótica da articulação voltada para o combate à fome. De acordo com Porto (2003), nos cursos de 40 horas para os Agentes Locais de Segurança Alimentar (ALSA) discutiam-se conceitos de fome, segurança alimentar e controle social, Projeto Fome Zero e PCA, CadÚnico e Sistema de Informação, porém, há relatos de dificuldades na prática Segundo representante do PCA-AL:

O MESA mandou capacitadores [...] sem nível superior, eram do PT. No estado eram melhores.

O gestor federal do PCA citou a importância de valorizar a experiência do PBA:

Foi ótimo já pegar a experiência do PBA. Então não tínhamos que capacitarno sistema de informação. Era uma parte mínima do curso.

Assim, como o esperado, a valorização de experiências anteriores mostrou-se mais eficaz do que a total ruptura por discordância política.

\section{Sistemas logísticos e operacionais}

Quanto à infra-estrutura na esfera federal, somente o PBA a considerou adequada. A centralização da Secretaria de Inclusão Educacional (Secrie), do PNBE, revelou infra-estrutura insuficiente, por haver necessidade de acompanhamento de mais de 5 mil municípios. Além disso, uma falha na estrutura normativa do programa foi não estabelecer procedimentos claros para que os municípios realizassem a seleção de beneficiários, permitindo manobras políticas em nível local (Britto, 2004). A descentralização é essencial, pois aumenta a disponibilidade de recursos humanos, materiais, financeiros, além de qualificar a implementação, por aproximar os locais de risco dos agentes que terão mais conhecimento da realidade. Nas entrevistas estaduais, a maioria do PBA e todos do PCA afirmaram que a infra-estrutura era inadequada, principalmente por falta de computadores, internet, impressora, recursos humanos capacitados, espaço para trabalhar e agência bancária no município.

Para um deputado, em pronunciamento ao Senado, em 2001, algumas preocupações deveriam ser consideradas na logística de entrega do benefício:

A grande maioria dos Municípios do Brasil não tem uma agência dos Correios, uma agência bancária ou uma lotérica. [...] Isso faz com que a família que ganha um cartão magnético tenha que se deslocar para outros Municípios a fim de receber o benefício.

Para o recebimento do recurso, os gestores estaduais do PBA informaram como dificuldade, o atraso ou a não entrega do cartão e/ou do benefício, a falta de agência ou funcionários da CAIXA, a existência de cartões com nomes incorretos, arquivos perdidos pela CAIXA, preenchimento repetido do cadastro, arquivoretorno não entregue e indicações políticas de possíveis beneficiários. Já os representantes estaduais do PCA, afirmaram, em maioria, que o abuso pelos donos de mercados ao ficarem com cartões e senhas ou cobrarem preços acima do normal dos beneficiários teria sido o maior obstáculo, seguido pelo não recebimento do benefício, inexistência de documentação, ausência de agência da CAIXA, recebimento do benefício por terceiros, falta de esclarecimento das agências para a população sobre a data de recebimento do benefício.

Parecem comuns a todos os programas as dificuldades em lidar com o cadastramento e os sistemas informatizados, especialmente da CAIXA, e com os sistemas dos ministérios, como a necessidade de listagem para escolha/priorização/acompanhamento de beneficiários. Segundo relatório de gestão do PNBE (Brasil, 2003b), o sistema do agente operador não ofereceu visibilidade de informações básicas aos municípios, tais como número de vagas ocupadas e disponíveis e a relação de famílias beneficiárias. De acordo com Montenegro (2004), em análise do PBA de Taubaté (SP), o fluxo dos dados era longo, demorado, com orientações desencontradas da CAIXA e das Secretarias locais, além da sensação de complexidade sentida pelos funcionários locais.

A maioria dos gestores estaduais do PBA e todos do PCA consideraram os programas inovadores. Representantes do PBA justificaram essa escolha principalmente por dois fatores: inserção social das pessoas/cidadania/participação e recurso direto ao beneficiário, o que confere autonomia. Para o PCA, o princi- 
pal diferencial foi o empoderamento dos beneficiários, seguido por empoderamento dos conselhos e existência do Comitê Gestor. No entanto, percebe-se no item sobre capacitações do PBA, que a inserção social e a mobilização não eram devidamente incentivadas junto aos municípios.

Sobre a autonomia ou o empoderamento dos beneficiários, foram muito discutidas as condicionalidades. Um questionamento considerado fundamental no Relatório do PBA (Coitinho e Leão, 2004) foi "como auxiliar as mães a realizarem melhores escolhas alimentares e não 'desperdiçarem' os recursos financeiros com produtos não saudáveis”. Essa questão foi avaliada pelo International Food Policy Research Institute (IFPRI), contratado pelo Ministério da Saúde para avaliar o PBA, verificando que famílias beneficiárias do programa utilizaram uma maior porcentagem de seu orçamento com alimentos do que as não-beneficiárias (Brasil 2004b).

Stein (2005) lembra que mecanismos estigmatizadores e constrangedores, como exigência de comprovação de pobreza, a mania de fraude em relação aos pobres e as condicionalidades exigidas, como se os beneficiários tivessem faltas a declarar, nunca foram veículos de inclusão social e sim de exclusão. Entrevista com representante de ONG indígena revela sua opinião sobre condicionalidades:

Levar para a escola. Que escola? O índio levar é no mínimo injusto. [Levar para vacinar] $\varepsilon$ se a vacina não chega? A idéia é boa, mas as condicionalidades não. A condição deveria ser estar passando fome. Até preencher todo o cadastro, as condicionalidades, [...] já morreu de fome.

Um relatório do PNBE cita exemplo em que uma mãe de três crianças teve R\$ 45,oo incorporados ao seu salário de R\$ 9o,oo: "Esse dinheiro vai melhorar principalmente a alimentação das crianças. Vai dar para comprar pão e leite todos os dias e também algum material que falte para o colégio" (Stal, 2002). Assim, mesmo o incentivo sendo do Ministério da Educação, percebe-se certa priorização para a alimentação, conforme também destacado em pesquisa da UNB sobre o PNBE (Brasil, 2003b).

As famílias analisam sua situação de forma integral, holística e não fragmentada. Nesse contexto, utilizam o recurso para atender suas necessidades mais imediatas. Quanto maior a desigualdade de renda, maiores as taxas de problemas relacionados à saúde (Starfield, 2004). A atenção médica tradicional impõe soluções técnicas baseadas no biologicismo e no desprezo ao saber e à iniciativa do doente e dos familiares para problemas sociais globais, preocupando-se com a expansão do direito à assistência, sem questionar o tipo de assistência que está sendo expandida (Vasconcelos, 2001).

Diante desse mesmo questionamento, o PCA exigia a apresentação de notas fiscais ou recibos de compra de alimentos, visando, conforme diversos relatos, "criar a cultura de cobrança das notas". Segundo gestor federal do programa:

Só alimentos [podiam ser comprados], assim era mais fácil de atingir somente as famílias que realmente precisavam para se alimentar. [...] [a verificação da compra de alimentos era acompanhada] voluntariamente pelo Comitê.

[esta exigência] foi posteriormente liberada por já existirem tantos outros problemas, como os [problemas] políticos.

Essa cobrança esteve presente nas rotinas de todos os entrevistados estaduais do PCA. Difundindo-se uma imagem de beneficiários com má intenção de uso do recurso:

Se não compravam alimentos é que não eram tão carentes assim.(PCA-BA.)

Dessa forma, o PCA não reconheceu a autonomia das pessoas, culpando os beneficiários pela sua situação de pobreza e fome. 0 investimento do benefício, que poderia ser útil para alguma atividade produtiva, não era considerado legítimo.

A gente identificou uma fábrica de doces parada só por causa do liquidificador que quebrou. (PCA-AL.)

O MESA criou os Consads (Consórcios de Segurança Alimentar e Desenvolvimento Local) para unir municípios, constituindo associação civil, sem fins lucrativos, após ampla articulação e capacitação, com 1 / 3 de representantes do poder público e 2/3 da sociedade civil, e organizar projeto sustentável para sua realidade. (Brasil, 2005). Os relatos estaduais sobre os Consads revelam que a proposta inicial era a sua vinculação ao PCA, porém, segundo a maioria dos depoimentos, na prática, o Consad não teve papel importante junto ao programa. Somente Alagoas relatou ter realizado 25 projetos de geração de renda associados ao PCA. 
A diferença entre concepção e prática aparece ao se verificar que os representantes do PCA afirmam reconhecer o DHAA e a SAN, mas restringem o uso do recurso à compra de alimentos. Na prática, violam direitos como saúde, moradia, transporte, educação, trabalho, lazer, inviabilizando o próprio DHAA.

A integralidade da atenção à saúde requer que os serviços de saúde estejam disponíveis e sejam prestados quando necessários para os problemas que ocorrem com freqüência. (Starfield, 2004).

A Comissão Intersetorial de Alimentação e Nutrição $(\mathrm{CIAN})^{1}$ do Conselho Nacional de Saúde (CNS) apresentou parecer sobre vantagem do PBA semelhante ao PNBE: Permite uma flexibilização na pauta de alimentos comprados pela família, respeitando a cultura [...] reforça o papel da mulher/mãe na gestão dos recursos, reconhecendo a capacidade das famílias de utilizá-lo de forma adequada [...]. Ao fazer isso, [...] reconhece que a [...] nutrição não passa, exclusivamente, pela compra direta de alimentos, mas por uma melhoria [...] da qualidade de vida.

A CIAN complementou com questões sobre as condicionalidades do PBA:

Os indicadores coletivos para o acompanhamento da eficácia e eficiência do projeto, referentes ao conjunto das ações básicas de saúde, como: cobertura e concentração de serviços de saúde (do pré-natal, da prevenção do câncer de colo uterino, da imunização, crescimento e desenvolvimento das crianças, do saneamento intra e peridomiciliar e outras), amplitude e impacto do PACS/PSF [Programa de Agentes Comunitários de Saúde/ Programa Saúde da Família] [...], devem prevalecer sobre os indicadores individuais (conduta da mãe de procurar e acatar as orientações dos serviços básicos de saúde e outros).

A restrição de uso do recurso tende a culpar a vítima pelo problema de fome, porém, como afirma Britto (2004), sem estratégias estruturantes, como o acesso a serviços, melhoria da educação, do emprego, da distribuição de renda, os PTR correm o risco de se tornarem mero conjunto de programas da moda com objetivos louváveis. Abaixo um exemplo de como o próprio recebimento do benefício corrói seu valor real:

[...] os beneficiários do PBA têm grande dificuldade para receber o benefício, principalmente os que moram na zona rural, tendo que percorrer, em média, $27 \mathrm{~km}$ para se deslocarem até o município [...] onde existe uma agência bancária. $O$ deslocamento causa uma despesa de $R \$$ 6,50, em média, o que representa 43,33\% do valor de uma Bolsa. (Controladoria Geral da União, 2006).

A fala demonstra uma lacuna que em princípio seria resolvida com deslocamento de funcionário da CAIXA para os municípios. No entanto, essa prática é de difícil implementação.

Quanto aos critérios de seleção de beneficiários e de responsáveis para o recebimento do recurso, diferentemente dos demais programas, um entrevistado federal do PCA afirmou:

Não precisava ser mulher, podia ser homem, idoso [...] havia famílias que tinham o pai, mas não tinham a mãe, ou de idosos abandonados [...] Tinha um público grande de famílias sem crianças.

Prates e Nogueira (2006) afirmam que, apesar da falta de informações disponíveis, há maior receptividade dos ministérios sobre a questão de gênero. Assinalam uma característica comum dos programas em focar a mulher no papel de mãe, geralmente para o recebimento do recurso. Segundo os autores, essa questão foi contornada pelo PCA, pois prioriza a mulher, mas não a vincula à sua condição de mãe. Klein (2005) mostra contradições em materiais e discursos do PNBE, nos quais ora as mulheres, reduzidas ao papel 'insubstituível' de mães, são re/posicionadas 'naturalmente' em tarefas domésticas, como responsáveis pela educação e cuidados de saúde de sua prole, ora devem desarticular o poder vigente e produzir transformações sociais. Segundo o autor, os homens, quando pais, são estigmatizados por não conseguirem prover necessidades familiares, incitando possível desobrigação pelos filhos. Urge, assim, não ignorar a discussão sobre o papel da mulher nos PTR, pois há o risco de focalizá-la sob uma ótica da classe e do sexo dominante (Soihet, 1997).

\section{Monitoramento, avaliação e controle social}

Quanto ao acompanhamento, as dificuldades citadas pelos gestores estaduais do PBA foram: digitação do acompanhamento no sistema, gerando subnotificação; não recebimento da agenda de compromissos; resis-

1 COMISSÃO INTERSETORIAL DE ALIMENTAÇÃO E NUTRIÇÃO. 110 a Reunião ordinária. Brasília, jun. 2001. 
tência da equipe por sobrecarga de trabalho; falta de conhecimento de municípios e estados de quem eram os beneficiários, não recebimento de acompanhamento do estado. Assim, apesar da real ausência de dados sobre o acompanhamento, os estados relatam que os municípios o estariam fazendo, porém sem registro. Isso, desde que soubessem a localização dos beneficiários, já que esse era um problema. Uma entrevistada do PNBE afirma que as contrapartidas dos municípios, quanto às ações educativas complementares aconteciam como cada escola entendesse, inclusive havia casos em que era "só o hasteamento da bandeira". Para o PCA, foram lembrados os seguintes obstáculos: transporte, recursos humanos, falta de troca de experiências entre nacional e estadual, abusos por comerciantes. Representantes do PCA confirmam dificuldades de acompanhamento:

Tínhamos dificuldade em acompanhar se as pessoas não precisassem mais. Se passavam a ter salário, por exemplo [...] as prefeituras não tinham informação de quem eram os beneficiários [...] tinha um problema de TI [tecnologia da informação] [...] apenas um computador podia receber os arquivos-retorno e essa informação se perdia em diversas Secretarias e [...] eram muitos computadores velhos, se estragavam, perdiam os arquivos. (Gestor Federal do PCA.)

Quem tava (sic) grávida antes [conforme digitado no cadastro único] não era mais, já tinha morrido [quando iam verificar]. (PCA-AL.)

Assim, o acompanhamento/cadastramento, que deveria, na maioria dos municípios, ser realizado pelo PSF, revelou que a equipe de saúde não foi reforçada para mais essa atribuição, sobrecarregando, primordialmente, o agente comunitário de saúde. Além disso, não deve ser esperado que nenhum profissional lide sozinho com todas as necessidades da população e sim de forma integrada com toda a rede de serviços (Starfield, 2004).

O monitoramento dos programas ocorreu por controles internos e externos aos órgãos, conselhos de controle social e avaliações técnicas organizadas pela esfera federal. Segundo seus gestores nacionais, o PCA não organizou avaliação devido a sua breve existência. Porém Alberto (2005) relata, após um ano de PCA em Guaribas (PI), aumento do consumo de leite/ carne, porém, sem mudança no consumo de frutas.

Para a avaliação do PNBE, a Secretaria de Inclusão
Educacional (Secrie) contratou, em 2002, a Fundação Universidade de Brasília. Em resumo, este estudo demonstrou que: o PNBE contribuiu para aumentar a matrícula no ensino fundamental e reduzir a evasão escolar; o controle social não acompanhava o programa, somente cumpria normas legais; os beneficiários concordaram com o benefício em dinheiro, apesar de considerarem o valor baixo; os profissionais de ensino não identificaram mudanças apreciáveis no aproveitamento escolar, no comportamento do bolsista nem na sua auto-estima; a maioria das crianças menores não deixou de trabalhar, pois os pais, preocupados com a "vadiagem", defendem o trabalho infantil; filhos bolsistas passaram a receber maior atenção da família. O uso mais freqüente do recurso foi material escolar, seguido de roupas, calçados e alimentos (Brasil, 2003b).

Sinteticamente, a avaliação do IFPRI sobre o PBA concluiu: eficiência quanto aos custos administrativos; maior gasto dos beneficiários com alimentos; dietas mais diversificadas; no entanto, verificou ganho de peso insuficiente, talvez pela crença dos beneficiários de que podiam perder o benefício caso a criança ganhasse peso (Morris e col., 2004; Brasil, 2004b). Somam-se a isso, os resultados das supervisões: compra de alimentos com o recurso; apenas 2,1\% declararam dificuldades quanto ao manuseio do cartão-magnético; 20,6\% declararam gastos de transporte para a retirada do benefício, gastando, cerca de R\$ 2,oo por vez; $84 \%$ não apresentaram dificuldades no acesso aos serviços de saúde; 83,8\% preferiam receber em dinheiro; 95,4\% declararam-se satisfeitos ou totalmente satisfeitos (Brasil, 2003c).

Auditorias foram realizadas nesses programas por controle externo e interno. No controle externo, aparecem órgãos como Controladoria Geral da União e Tribunal de Contas da União (TCU). O PNBE controlava internamente o programa por meio da Coordenação Geral de Monitoramento e Auditoria da Diretoria de Gestão da Secrie com apoio da Secretaria Federal de Controle Interno (SFCI), por meio de denúncias e auditoria in loco por amostragem (Brasil, 2003b). O PBA constituiu a Coordenação de Acompanhamento de Convênios e Auditorias para acompanhar, verificar, encaminhar e registrar ocorrências quaisquer que fossem suas procedências (Brasil, 2004b, 2004C). Faziam, ainda, supervisões periódicas. 
Quanto ao controle social em estados e municípios, a legislação do PNBE exigia a criação ou a designação de um conselho, não necessariamente o de educação; para o PBA era o Conselho de Saúde; para o PCA, o Comitê Gestor.

Segundo entrevista, o PNBE não tinha controle social na esfera federal, somente nos municípios, para acompanhamento da freqüência escolar, chegando a $83 \%$ de transmissão de dados sobre freqüência para a esfera federal (Brasil, 2003b). Entrevistados do PBA e do PCA indicam o envolvimento do controle social desde a formulação até a execução. Os Comitês Gestores do PCA, muito elogiados pelos gestores estaduais, multiplicavam conceitos como direitos humanos e cidadania, acompanhavam as condicionalidades e as famílias, localizavam famílias não cadastradas, corrigiam o cadastro, identificavam pessoas sem registro civil e validavam beneficiários cadastrados pelo município. Formado por $2 / 3$ de representantes da sociedade civil, o comitê confrontava o poder local, chegando diversas vezes "às vias de fato" e criando resistência para a continuidade do cadastramento em algumas prefeituras (Porto, 2003). O Comitê Gestor permitiu um avanço real na construção do controle social ao codividir as responsabilidades na operacionalização do programa.

As entrevistas revelam que a avaliação e o monitoramento dos programas começaram a entrar na rotina do planejamento das políticas públicas no Brasil, porém, como afirma Stein (2005), ainda vinculados à exigência dos organismos internacionais para a concessão do apoio financeiro, sem um sistema de avaliação padrão ou publicização regular dos resultados para a população. Havia mecanismos regulares como as visitas de supervisão do PBA, papel também passado às Coordenações Estaduais e Municipais e ao controle social, mas ainda precário.

Correções foram implementadas, como a exclusão de beneficiários e a flexibilização do controle de notas fiscais no PCA. Porém, mecanismos mais eficientes de correção de irregularidades sem prejuízo a beneficiários ainda precisam ser discutidos:

Tendo identificado a fraude [em município do Ceará], o $M E C$ imediatamente bloqueou o pagamento [do PNBE] [...], prejudicando todas as crianças. (Parlamentar em pronunciamento ao Senado, em setembro de 20o1.)

\section{Conclusão}

O estudo identificou que apenas o Programa Bolsa Alimentação se preocupou diretamente com a questão da saúde, sendo uma falha na organização dos demais programas (como explicitado no Consea) a desvalorização dessa questão.

A saúde deve ser entendida como resultante das condições de alimentação, habitação, educação, renda, meio ambiente, trabalho, transporte, emprego, lazer, liberdade, acesso e posse da terra e acesso a serviços de saúde. Da mesma forma a Segurança Alimentar e Nutricional implica em considerar tanto os fatores biológicos quanto o acesso aos demais direitos acima citados. Assim, a superação das causas estruturantes da pobreza, que abalam diretamente o corpo com as doenças, a desnutrição, a fome não podem ser reduzidas visando ao atendimento somente de certos aspectos orientados para educação, para trabalho, ou para a alimentação. A insegurança quanto ao uso do recurso transferido e a exigência de condicionalidades reduzem a discussão mais ampla essencial à prática intersetorial. A simples vinculação dos programas a condicionalidades melhora o acesso e a garantia dos serviços, porém torna os beneficiários dependentes desses serviços e de seus profissionais. No entanto, a atenção à saúde, a assistência social e a educação são obrigações dos governos, sendo esse o enfoque a ser priorizado. A articulação intersetorial é fundamental para a modificação de condições estruturantes, que limitam o crescimento digno dos indivíduos.

Merece aprofundamento a discussão sobre o controle de irregularidades e de efeitos perversos dos benefícios sobre as relações econômicas e sociais, além de abusos por comerciantes locais. Para isso é preciso garantir o respeito à autonomia dos beneficiários na identificação e realização de suas aspirações para satisfazer suas necessidades. Outro aspecto que não deve ser desconsiderado é a importância dos princípios que regem o SUS, no caso a descentralização, pois desconsiderá-lo é esquecer todo o movimento da reforma sanitária exigido pela sociedade brasileira, que trouxe novos desafios à saúde pública.

Um grande desafio, não somente dos PTR, mas também das demais políticas e programas, é a diversidade cultural do povo brasileiro. Os programas apresen- 
tam um desenho urbano, não incluindo, por vezes até excluindo e punindo, pessoas com menor acesso à cidadania, revelando seleção entre os portadores de direito. Não são, portanto, formulados para os mais excluídos levando à necessidade de adequação da população ao programa e não o contrário. Somente quando se alcançar todos os portadores de direito, envolvendo-os desde a formulação das políticas até a avaliação, poderá se reduzir a fome, sem reproduzir a pobreza por gerações. Assim, é preciso haver uma garantia de renda mínima a todos os cidadãos sem necessidade de comprovação e de "marcas" de pobreza.

\section{Referências}

AGUIAR, M.; ARAÚJO, C. H. (Org.). Bolsa escola: education to confront poverty. Brasília, DF: UNESCO, 2002.

ALBERTO, N. S. M. C. Resultados do Programa Fome Zero/Cartão Alimentação sobre a disponibilidade de alimentos e de nutrientes em famílias do município de Guaribas - Piauí. 2005. Dissertação (Mestrado em Ciências e Saúde) - UFPI, Teresina, 2005.

BALSADI, O. V.; DEL GROSSI, M. E.; TAKAGI, M. O Programa Cartão Alimentação (PCA) em números: balanço de sua implementação e contribuições para as políticas sociais. In: CONGRESSO DA SOBER, 42., 2004, Cuiabá. Anais... Cuiabá: UFMT, 2004. p. 81-97.

BRASIL. Ministério da Saúde. ABC do SUS. Brasília, DF, 1990.

BRASIL. Lei ${ }^{\circ}$ 10.219, de 11 de abril de 2001. Cria o Programa Nacional de Renda Mínima vinculada à educação - Bolsa Escola, e dá outras providências. Diário Oficial [da] República Federativa do Brasil, Brasília, DF, 12 abr. 2001 a. Seção 1, p. 1.

BRASIL. Medida Provisória nº 2.206, de 10 de agosto de 2001. Cria o Programa Nacional de Renda Mínima vinculado à Saúde: Bolsa-Alimentação. Diário Oficial [da] República Federativa do Brasil, Brasília, DF, 13 ago. 2001b. Seção 1, p. 3 .

BRASIL. Medida provisória $n^{\circ} 108$ de 27 de fevereiro de 2003. Cria o Programa Nacional de Acesso à Alimentação - Cartão Alimentação. Diário Oficial [da] República Federativa do Brasil, Brasília, DF, 28 fev. 2003a. Seção 1, p. 1.
BRASIL. Ministério da Educação. Secretaria de Inclusão Educacional. Relatório de gestão 2003. Brasília, DF, 2oozb.

BRASIL. Ministério da Saúde. Coordenação Geral da Política de Alimentação e Nutrição. Bolsa Alimentação - maio 2003. Brasília, 2003C. Apresentação sobre o programa Bolsa Alimentação. 902Kb. Arquivo em PowerPoint.

BRASIL. Lei $n^{\circ}$ 10.836, de 9 de janeiro de 2004. Cria o Programa Bolsa Família e dá outras providências. Diário Oficial [da] República Federativa do Brasil, Brasília, DF, 12 jan. 2004 a. Seção 1, p. 1.

BRASIL. Ministério da Saúde. Avaliação do programa Bolsa-Alimentação: primeira fase. Brasília, DF, 2004b.

BRASIL. Ministério da Saúde. Secretaria de Atenção à Saúde. Departamento de Atenção Básica. Relatório de Gestão - 2003 Coordenação Geral da Política de Alimentação e Nutrição. Brasília, DF, 2004C. Disponível em: <http://dtr2oo4.saude.gov.br/ nutricao/documentos/gestao_2003.pdf>. Acesso em: 07 mar. 2006.

BRASIL. Ministério do Desenvolvimento Social. Consórcio de Segurança Alimentar e Desenvolvimento Local (CONSAD). 2005. Disponível em: <http:// www.mds.gov.br/secretarias/secretariao1_og.asp >. Acesso em: 4 fev. 2005 .

BRITTO, T. F. Conditional cash transfers: why have they become so prominent in recent poverty reduction strategies in Latin America. The Hague: Institute of Social Studies, 2004. (Working Paper Series, 390).

CHAIBUB, J. R. W. Programas de transferência de renda e o enfrentamento da pobreza no Brasil: análise dos processos de formação e formulação do Programa Nacional de Bolsa Escola (2001-2002). 2004. Dissertação (Mestrado em Política Social) Universidade de Brasília, Brasília, DF, 2004.

COIMBRA, M. A. Será que o marxismo responde à pergunta de como surgem as políticas sociais? In: ABRANCHES, S. H.; SANTOS, W. G.; COIMBRA, M. A. (Org.). Política social e combate à pobreza. Rio de Janeiro: Jorge Zahar, 1987. p.105-126. 
COITINHO, D.; LEÃO, M. O Programa Bolsa

Alimentação: um relato de seu desenho, implementação, impacto e custos. Brasília, DF:

Observatório de Políticas de Segurança Alimentar e

Nutrição da Universidade de Brasília, 2004.

CONTROLADORIA GERAL DA UNIÃO. Principais

constatações. Disponível em: <http://

www.cgu.gov.br/AreaAuditoriaFiscalizacao/

ExecucaoProgramasGoverno/Sorteios/Municipios/

Sorteio5/sorteio5_al_jacuipe.PDF $>$. Acesso em: o8

mar. 2006.

DRAIBE, S. M. Avaliação de implementação: esboço de uma metodologia de trabalho em políticas públicas. In: BARREIRA, M. C. R.; CARVALHO, M. C. B. (Org.). Tendências e perspectivas na avaliação de políticas e programas sociais. São Paulo: IEI: PUCSP, 2001. p. 13-42.

FAGNANI, E. Avaliação do ponto de vista do gasto e financiamento das políticas sociais. In: RICO, E. Avaliação de políticas: uma questão em debate. São Paulo: Cortez, 1998. p. 119-130.

INSTITUTO DE CIDADANIA. Projeto Fome Zero: uma proposta de política de segurança alimentar para o Brasil. São Paulo, 2001.

IPEA - INSTITUTO DE PESQUISA ECONÔMICA APLICADA. Políticas sociais: acompanhamento e análise, v. 6, p. 10-11, 2003. Disponível em: <http:// www.ipea.gov.br/pub/bps/bps_o6.pdf $>$. Acesso em: 5 fev. 2006.

IPEA - INTITUTO DE PESQUISA ECONÔMICA

APLICADA. Objetivos de desenvolvimento do milênio: relatório nacional de acompanhamento. Brasília, DF, 2004.

KLEIN, C. A produção da maternidade no Programa Bolsa-Escola. Revista Estudos Feministas, Florianópolis, v. 13, n. 1, p. 31-52, jan./abr. 2005.
MONTENEGRO, A. M. R. A gestão de saúde e informação na implementação do programa bolsa alimentação do município de São José dos Campos: estudo de caso da Secretaria Municipal de Saúde. 2004. Dissertação (Mestrado em Gestão e Desenvolvimento Regional) - Departamento de Economia, Contabilidade e Administração da Universidade de Taubaté, Taubaté, 2004. Disponível em: <http://www.unitau.br/prppg/cursos/ppga/ mestrado/2004/montenegro_angela_maria_da _rocha.pdf >. Acesso em: 29 jun. 2006.

MORRIS, S. S. et al. Conditional Cash Transfers are associated with a small reduction in the rate of weight gain of preschool children in Northeast Brazil. The Journal of Nutrition, Bethesda, v. 134, n. 9, p. 2336-2341, 2004.

OFFE, C.; LENHARDT, G. Teoria do Estado e política social: tentativas de explicação político-sociológica para as funções e processos inovadores da política social. In: OFFE, C. Problemas estruturais do Estado capitalista. Rio de Janeiro: Tempo Brasileiro, 1984. p. 53-70.

OSZLAK, O.; O’DONNELL, G. Estado y políticas estatales en América Latina: hacia una estrategia de investigación. Buenos Aires: CEDES, 1976.

(Documentos CEDES, 4).

PORTO, E. B. D. Fome Zero e controle social: a experiência dos comitês gestores do Programa Cartão Alimentação. Res Pvblica número 5, p.117-141, 2003. Disponível em: <http://www.anesp.org.br/ sites/300/394/Revista\%2orespvblica/ respublica5pdf.pdf $>$. Acesso em: 9 mar. 2006.

POULANTZAS, N. O Estado, o poder, o socialismo. 2. ed. Rio de Janeiro: Graal, 1985.

PRATES, C. A.; NOGUEIRA, M. B. B. Os programas de combate a pobreza no Brasil e a perspectiva de gênero no período 200o-2003: avanços e possibilidades. Disponível em: <http://www.eclac.cl/ publicaciones/UnidadMujer/9/LCL2309/ lcl2309p.pdf>. Acesso em: 29 jun. 2006. 
STARFIELD, B. Atenção primária: equilíbrio entre necessidades de saúde, serviços e tecnologia.

Brasília, DF: UNESCO Brasil: Ministério da Saúde, 2004.

SILVA, M. O. Z. S. A política social brasileira no século XXI: a prevalência dos programas de transferência de renda. São Paulo: Cortez, 2004.

SOIHET, R. História, mulheres, gênero: contribuições para um debate. In: AGUIAR, N. Gênero e ciências humanas: desafio às ciências desde a perspectiva das mulheres. Rio de Janeiro: Record: Rosa dos Tempos, 1997. p. 95-114.

STAL, I. L. Bolsa Escola como alternativa de inclusão social. In: CONGRESO INTERNACIONAL DEL CLAD SOBRE LA REFORMA DEL ESTADO Y DE LA ADMINISTRACIÓN PÚBLICA, 7., 2002, Lisboa, Portugal. Anais eletrônicos... Disponível em: <http:// unpan1.un.org/intradoc/groups/public/documents/ CLAD/cladoo44530.pdf>. Acesso em: 1 mar. 2006.

STEIN, R. H. As políticas de transferência de renda na Europa e na América Latina: recentes ou tardias estratégias de proteção social? 2005. Tese (Doutorado em Sociologia) - Universidade de Brasília, Brasília, DF, 2005.
SUPLICY, E. M. Renda de cidadania: a saída é pela porta. 2. ed. rev. São Paulo: Cortez: Fundação Perseu Abramo, 2002.

VALENTE, F. L. S. A política de insegurança alimentar e nutricional no Brasil de 1995 a 2002. 2003. Disponível em: www.fomezero.gov.br/ download/pol_inseg_alimentar_Flavio_Valente.pdf. Acesso em: 20 jun. 2006.

VALENTE, F. L. S. Direito humano à alimentação: desafios e conquistas. São Paulo: Cortez, 2002.

VASCONCELOS, E. M. (Org.). A saúde nas palavras e nos gestos: reflexões da rede educação populare saúde. São Paulo: HUCITEC, 2001.

VASCONCELOS, E. M. Estado e políticas sociais no capitalismo: uma abordagem marxista. Revista Serviço Social e Sociedade, São Paulo, ano 9, n. 28, p. 5-32, 1988.

VASCONCELOS, F. A. G. Combate à fome no Brasil: uma análise histórica de Vargas à Lula. Revista de Nutrição, Campinas, v. 18, n. 4, p. 439-457, jul./ago. 2005. 